\title{
The Challenge of Obesity and Asthma in Children and Adolescents
}

\author{
Erick Forno, MD, MPH and Juan C. Celedón, MD, DrPH
}

Division of Pulmonary Medicine, Allergy, and Immunology, Children's Hospital of Pittsburgh of UPMC, University of Pittsburgh School of Medicine, Pittsburgh, PA, USA.

\section{ABSTRACT}

Obesity and asthma each affect millions of people worldwide and the prevalence of both diseases has substantially risen in the last few decades. Solid epidemiological and experimental evidence strongly suggest that obesity increases asthma risk and severity, leading to growing recognition of an obese asthma phenotype. This phenotype is complex and multifactorial, differs between children and adults, and likely encompasses several sub-phenotypes. In this article, we will review the characteristics of obese asthma in children, as well as some of its underlying pathways. Furthermore, we will discuss some remaining challenges in the research, diagnosis, and management of obese asthma in children. (BRN Rev. 2018;4:70-83)

Corresponding author: Erick Forno, erick.forno@chp.edu

Key words: Asthma. Childhood asthma. Metabolic syndrome. Obese asthma. Obesity. 


\section{INTRODUCTION}

Obesity is a chief risk factor for the metabolic syndrome, cardiovascular disease, and diabetes. The processes that lead to these complications may start as early as in childhood. In the United States (U.S.), approximately $17 \%$ of children are obese (defined as a body mass index $[\mathrm{BMI}] \geq 95^{\text {th }}$ percentile for age and sex) and another $15 \%$ are overweight $\left(B M I \geq 85^{\text {th }}\right.$ percentile and $<95^{\text {th }}$ percentile) ${ }^{1}$. In Catalonia, the prevalence of overweight and obesity is $\sim 15 \%$ and $\sim 20 \%$, respectively, and tends to be higher among children with parents of low socio-economic status or lower education levels ${ }^{2}$. While obesity is currently defined using BMI, recent studies have suggested that this definition may be unreliable and that metabolic dysfunction may be more important than adipose tissue mass ${ }^{3-5}$.

Asthma affects $~ 9.5 \%$ of children in the U.S. ${ }^{6}$ and the prevalence of asthma can be as high as $\sim 30 \%$ in other countries; ; in Spain, the prevalence of asthma has been reported as ranging from $9.5 \%$ to $16 \% 8,9$. Based on several longitudinal epidemiological studies, obesity is now recognized as a risk factor for asthma and associated with worse asthma outcomes ${ }^{10-18}$. However, it is not clear whether this association holds true for all children with obesity and asthma. In this review, we will first summarise our current understanding of obese asthma in children, and then discuss some of the challenges in the study and management of this phenotype.

\section{THE OBESE ASTHMA PHENOTYPE}

Among children and adults with asthma, obesity has been associated with worse asthma severity, more frequent exacerbation $s^{19,20}$, poor asthma control ${ }^{21}$, worse quality of life ${ }^{22}$, longer hospital length of stay, and a higher risk of requiring intubation and mechanical ventilation $^{23}$. Obese children with asthma also seem to have a reduced response to asthma medications. Analysing data from the Childhood Asthma Management Program (CAMP), we reported that obese asthmatic children had a diminished response to inhaled corticosteroids (ICS) and that those participants had more frequent exacerbations and need for oral steroid courses for asthma ${ }^{24}$. Obese asthmatic adolescents may also have reduced response to bronchodilators compared with non-obese adolescents with asthma ${ }^{25}$. However, much like obesity and asthma, obese asthma (in both children and adults) is likely a complex phenotype with numerous contributing risk factors and underlying pathways (Fig. 1).

\section{THE EARLY-LIFE INFLUENCE OF MATERNAL OBESITY}

Several longitudinal epidemiological studies have reported associations between maternal obesity and increased risk of asthma during childhood. In a recent meta-analysis of over 100,000 mother-child dyads, we reported that maternal obesity during pregnancy, as well as excess weight gain, were independently associated with increased risk of recurrent wheezing and asthma in the offspring ${ }^{21}$. A recent analysis found that only a part of this association is mediated by the child's own $\mathrm{BMI}^{26}$, suggesting that there are other in utero or early-life factors beyond the child's own obesity. Babies born to obese mothers have fewer cord blood eosinophils and CD4+ T-cells, higher levels of interleukin (IL)-6 and interferon (IFN-)o2, 


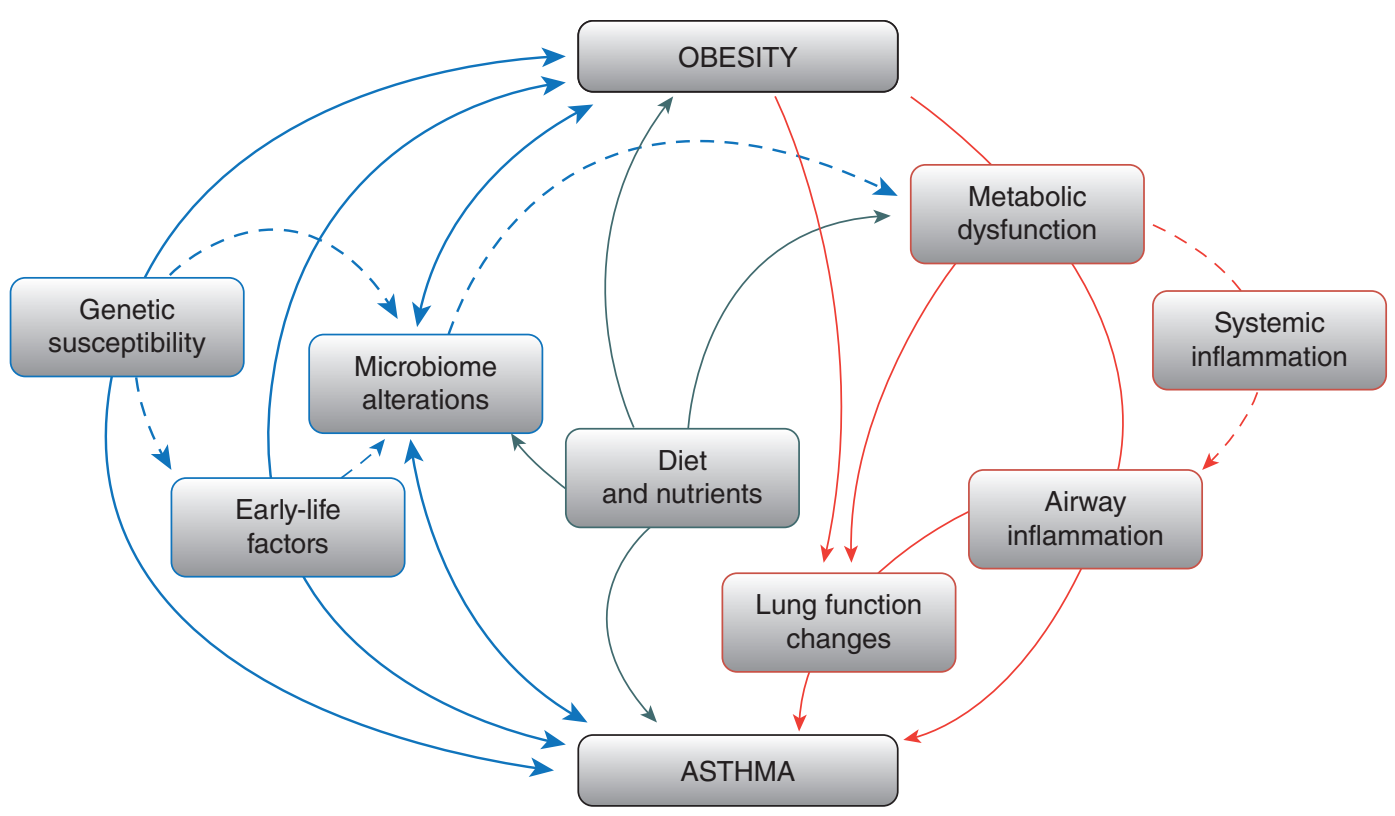

Figure 1. Obese asthma underlying pathways.

Shown are general pathways and mechanisms involved in the obese asthma phenotype. Genetic susceptibility and early-life (including in utero) factors can predispose to both obesity and asthma. Microbiome changes can cause or be a consequence of either disease and can also contribute to metabolic dysregulation. Obesity can lead to metabolic dysfunction and systemic inflammation, both of which can increase airway inflammation, asthma risk, or asthma severity. Lung function changes can be the result of anatomical/developmental alterations in obesity and can also be influenced by metabolic dysregulation.

and abnormal monocyte and dendritic cell responses ${ }^{27}$. Placenta and newborn from obese women also show increased oxidative stress and higher triglyceride levels ${ }^{28}$. More recently, Costa et al. ${ }^{29}$ reported gene expression changes in umbilical vein endothelium from infants born to overweight or obese mothers compared with those born from normal-weight women; pathway analysis suggested these changes were related to mitochondrial and lipid metabolism. These early-life alterations could also explain reports that rapid or excess weight gain as early as in infancy are associated with increased risk of wheezing ${ }^{30}$.

\section{OBESITY AND LUNG FUNCTION}

Childhood obesity has significant effects on pulmonary function. In the 1990s and 2000s, investigators started reporting that higher weight or higher BMI were associated with increasing forced expiratory volume in one second $\left(\mathrm{FEV}_{1}\right)$ and forced vital capacity $(\mathrm{FVC})$, and with lower $\mathrm{FEV}_{1} / \mathrm{FVC}$ ratios, in children with and without asthma ${ }^{31,32}$. We recently reported an increased prevalence of airway dysanapsis in overweight and obese children with and without asthma ${ }^{33}$. The term was coined to describe an incongruence between the growth of the diameter of the airways and 
the volume of the lungs ${ }^{34}$. Dysanapsis has been reported among breath-hold divers, who use techniques that hyperinflate their lungs in order to provide extra oxygen and pressure protection $^{35}$. In children from six independent cohorts, we found that obesity was associated with normal or supra-normal $\mathrm{FEV}_{1}$ and $\mathrm{FVC}$, with larger increases in FVC leading to a low $\mathrm{FEV}_{1} /$ $\mathrm{FVC}$ ratio $^{33}$. Among obese children with asthma, dysanapsis was also associated with higher asthma symptoms, morbidity, and medication use.

These findings are quite different from adults, in whom obesity has been associated with a restrictive deficit characterized by low lung volumes, symmetrically reduced $\mathrm{FEV}_{1}$ and $\mathrm{FVC}$, and a normal $\mathrm{FEV}_{1} / \mathrm{FVC}$ ratio ${ }^{36,37}$. In a recently published meta-analysis, we reported that age indeed modifies the association between obesity and spirometry results: in adults, overweight/obesity was associated with lower $\mathrm{FEV}_{1}$ and $\mathrm{FVC}$ with a normal $\mathrm{FEV}_{1} / \mathrm{FVC}$ ratio, whereas in children there was a lower $\mathrm{FEV}_{1} / \mathrm{FVC}$ ratio with normal or slightly higher $\mathrm{FEV}_{1}$ and $\mathrm{FVC}^{38}$. Age (and likely disease onset or duration) are also important modifiers of the relation between obesity and lung function in subjects with asthma: Strunk et al. ${ }^{39}$ reported that, among participants in the CAMP who were not obese during the trial, those who became obese afterwards had significant decreases in $\mathrm{FEV}_{1}$ and $\mathrm{FEV}_{1} / \mathrm{FVC}$ ratio at $\sim 26-30$ years of age, compared with those who never became obese, with no significant changes in FVC.

Only a few studies in paediatrics have evaluated the effect of obesity on lung volumes, and most have reported reductions in functional residual capacity (FRC) and residual volume $(\mathrm{RV})$, with little or no effect on total lung capacity (TLC) ${ }^{40-42}$. Thus, further research is needed in this area. Likewise, it is unclear whether excess weight leads to increased airway hyperresponsiveness (AHR) in children ${ }^{43,44}$ and further research is needed on the topic.

\section{INFLAMMATION AND METABOLIC DYSFUNCTION}

Many consequences and complications of obesity arise from its inflammatory milieu. Like adults, obese children are predisposed to insulin resistance and systemic inflammation. Thus, it has been proposed that asthma in the obese results from such systemic inflammatory state, rather than classical type $2 \mathrm{~T}$ helper (Th2) atopic airway inflammation. Several studies have reported that obese children with asthma tend to have increased type $1 \mathrm{~T}$ helper (Th1) responses ${ }^{45}$ and that some of those effects are mediated by metabolic dysregulation, particularly in more markedly obese adolescents ${ }^{46}$. However, others have described that obesity is associated with higher risk of atopic sensitization in children and adults ${ }^{47,48}$. Our group analysed data from adolescents who participated in the U.S. National Health and Nutrition Examination Survey (NHANES) and reported that high BMI was linked to asthma risk only among those without evidence of eosinophilic airway inflammation, as measured by exhaled nitric oxide (FeNO) (Fig. 2). Yet, in adolescents with asthma, being obese and having elevated FeNO synergistically worsened asthma control and severity ${ }^{49}$. This suggests that both Th2 and non-Th2 inflammatory responses may play a role in obese asthma.

Adipose tissue, rather than an inert storage of energy reserves, is very active metabolically, producing adipokines and other inflammatory 
A

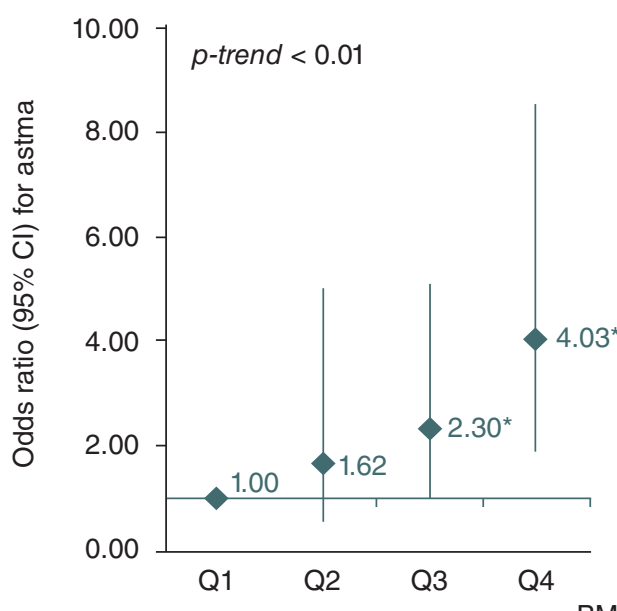

B

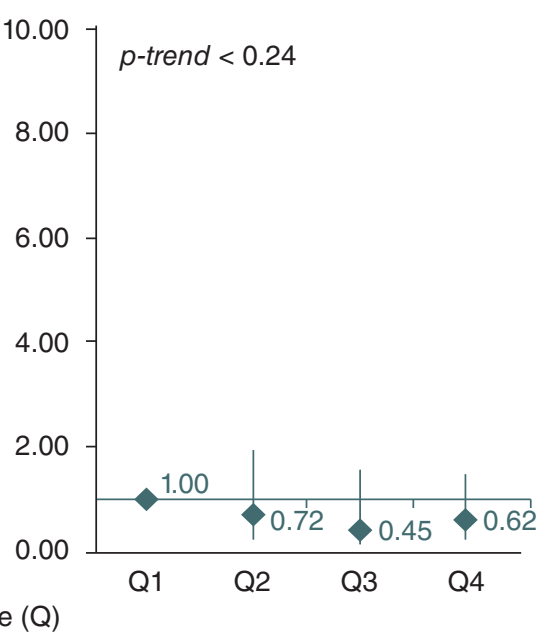

FIgURE 2. Obesity, eosinophilic airway inflammation and asthma risk. A) Increased odds of asthma with higher BMI z-score quartiles among children with normal FeNO $(<20 \mathrm{ppb})$. B) No association between BMI z-score increase and the odds of asthma among those with high FeNO (Reprinted with permission of the American Thoracic Society, from Han et al., Am J Respir Crit Care Med 2014. Copyright (C) 2018 American Thoracic Society).

BMI: body mass index; FeNO: exhaled nitric oxide.

cytokines that may affect the lungs and the immune system, including eosinophils, macrophages, and innate lymphoid cells (ILCs) (Fig. 3$)^{50}$. Leptin is markedly increased in many obese subjects, and higher serum leptin levels have been associated with lower lung function in obese children and adolescents ${ }^{51,52}$. Conversely, adiponectin has anti-inflammatory properties and is decreased in obesity, being associated with less exercise-induced bronchospasm in children with asthma ${ }^{53}$, fewer exacerbations, and fewer symptoms ${ }^{54}$. Changes in adipokine production and balance may alter eosinophil survival and migration to the lungs and may induce activation of macrophages to produce systemic and airway inflammation. Unfortunately, most studies to date have been cross-sectional, and we do not know whether these changes are causal (i.e. higher leptin or lower adiponectin have an effect on the lungs leading to increased asthma morbidity) or whether they simply act as biomarkers (i.e. the changes are not causal but may reflect the underlying changes at play).

Metabolic dysfunction may be more important in obese asthma than mere excess fat mass ${ }^{55}$. Hyperglycaemia and the body's attempt to compensate by elevating insulin levels may lead to airway epithelial damage and proliferation of airway smooth muscle, which in turn may worsen AHR and airway remodelling ${ }^{56-58}$. We previously reported that insulin resistance and metabolic syndrome are associated with decreased spirometry in adolescents, and that this negative effect may be synergistic among adolescents with asthma ${ }^{59}$. Insulin may also increase AHR by altering parasympathetic airway tone and regulation ${ }^{60}$. IL-6 is elevated in obese subjects with metabolic dysregulation, and in adults it has been associated with increased asthma severity ${ }^{61,62}$. Furthermore, IL-6 


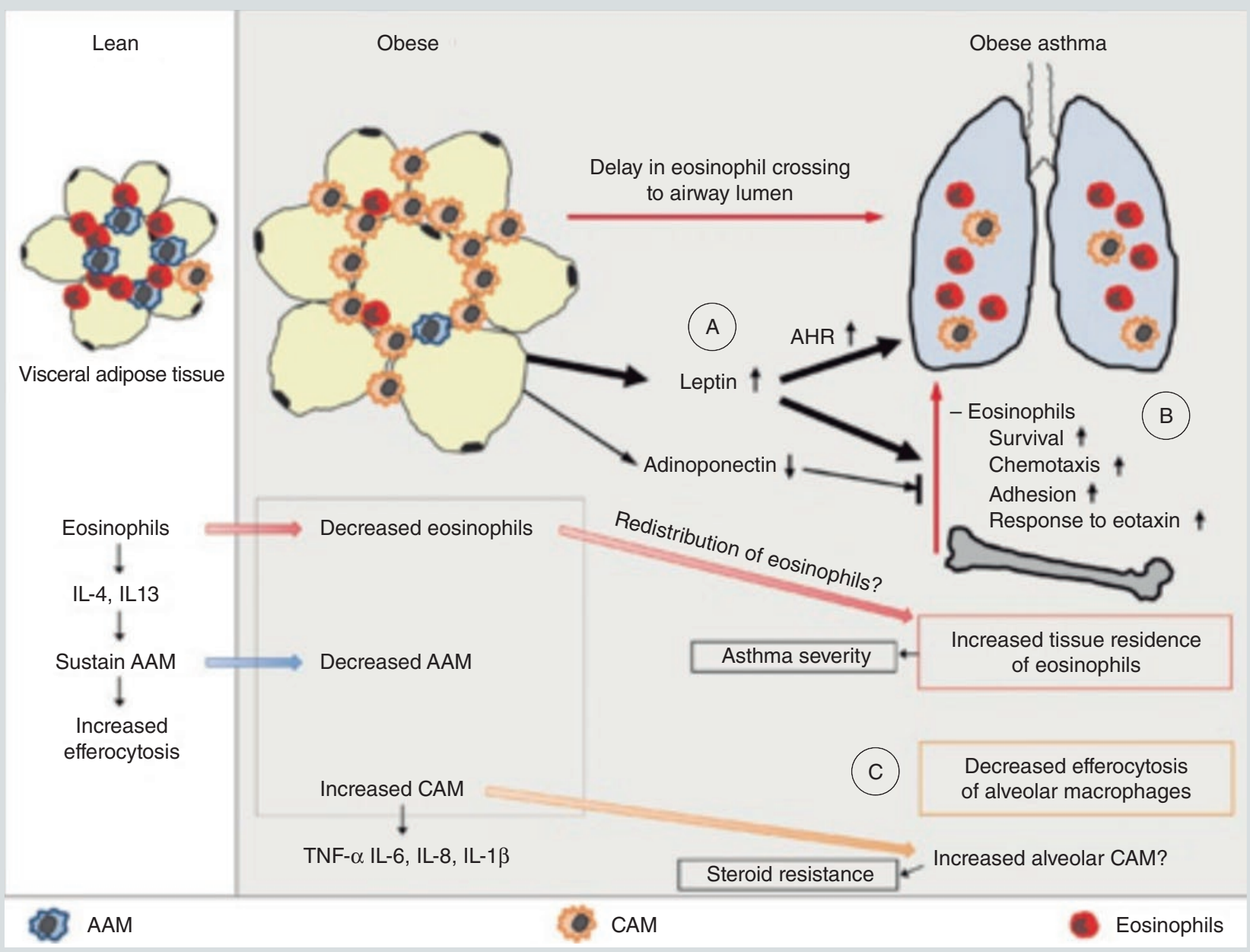

Figure 3. Proposed role of adipokines linking obese adipose tissue and asthma. A) Adipokines can regulate eosinophil and macrophage activation and function. B) Adipokine changes may result in migration and accumulation of eosinophils in the lung tissue. C) Activated macrophages in obese adipose tissue may play an important role in systemic and airway inflammation (reprinted with permission from Kim SH et al. ${ }^{50}$.

AAM: alternatively-activated macrophages. AHR: airway hyper-reactivity; CAM: classically-activated macrophages; IL: interleukin; TNF- $\alpha$ : tumour necrosis factor alpha.

trans-signalling increases airway smooth muscle expression of genes associated with immune responses, hypoxia, and airway remodelling ${ }^{63}$.

\section{DIET AND NUTRIENTS}

Dietary factors are clearly linked to obesity and some of these dietary patterns have also been associated with asthma. A diet poor in grains and vegetables but rich in consumption of sweets and processed dairy products has also been associated with higher risk of asthma ${ }^{64}$. Similarly, frequent intake of beverages with high sugar content has been linked to asth$\mathrm{ma}^{65}$. On the contrary, breastfeeding has been reported as a protective factor for both diseases, but the findings for asthma have been more inconsistent (perhaps partly due to variable accounting for introduction of foodstuff across 
studies) ${ }^{66,67}$. Likewise, a Mediterranean diet, which is a protective risk factor against obesity and its metabolic complications, has been associated with lower risk of recurrent wheezing and asthma in children and adults ${ }^{68,69}$.

With regard to specific nutrients, obese persons tend to have lower vitamin $\mathrm{D}$ levels ${ }^{70}$, and low maternal vitamin D levels during pregnancy are associated with higher risk of obesity in their offspring ${ }^{71}$. Conversely, vitamin D insufficiency has been associated with severe asthma exacerbations and worse asthma outcomes $^{72-75}$. Furthermore, a meta-analysis of two recent clinical trials showed that vitamin D supplementation during pregnancy leads to $25 \%$ lower risk of asthma or recurrent wheezing in children up to three years of age; the strongest effect ( $\sim 45 \%$ reduction) was seen among children from women with sufficient levels $(\geq 30 \mathrm{ng} / \mathrm{ml})$ at the start of the trials ${ }^{76,77}$. Intake of micronutrients such as vitamin $\mathrm{E}$ or zinc during pregnancy has also been linked to lower odds of asthma ${ }^{69}$. Other nutrients that may be involved in obese asthma include Omega-3 and Omega- 6 fatty acids, which have been associated with lower and higher risks of asthma, respectively ${ }^{78,79}$. Beyond observational analyses, studies such as an ongoing randomized controlled trial (RCT) of Omega-3 fatty acids for obesity and asthma in adolescents and young adults (NCT01027143) will help ascertain whether the type of fat in the diet is as important as the total amount of fat ingested.

\section{THE MICROBIOME}

In recent years, increasing attention has been paid to the interactions between the microbiome and the host's immune system, with the hypothesis that altered microbial composition -or altered interactions with the microbiomepredisposes to the development of non-infectious diseases, including asthma and obesity. Frequent antibiotic use during pregnancy or in infancy has been associated with both obesity and asthma ${ }^{80,81}$. Several longitudinal cohorts have shown that changes in gut microbial composition, diversity, or abundance in the first few months of life may increase the risk of wheezing or asthma ${ }^{82}$. These changes may be in part determined by genetic predisposition, dietary patterns, and/or environmental exposures. Changes in the gut microbiome may lead to increased risk of obesity and asthma via several pathways, including dietary fibre fermentation and production of short-chain fatty acids ${ }^{83}$. Whether the overall composition of the bacterial ecosystem or the abundance of specific bacterial species modulates the risk of atopy and asthma is unclear ${ }^{84}$, and there is ongoing debate regarding the best methods to ascertain bacterial quantity and diversity for microbiome studies ${ }^{85}$.

Whether microbiome changes associated with asthma are causal, coincidental, or the product of confounding, however, is unknown. Probiotic supplementation in early life (in utero and early infancy) may help reduce the risk of atopic sensitisation and eczema, but may not help prevent asthma ${ }^{86,87}$. An ongoing trial of supplementation with bacterial extracts in infancy (NCT02148796) could help clarify whether manipulation of the gut flora (or modulation of the interactions between the gut flora and the immune system) reduces the risk of asthma. Likewise, a small pilot study is currently underway to study the effect of probiotic supplementation to modulate the airway microbiome in obese asthmatic adults (NCT03157518); this study may help understand whether modulation of the 
airway microbiome in obese asthmatics leads to improved asthma outcomes.

\section{GENETICS AND GENOMICS}

With both diseases having a substantial hereditary element, investigators have long hypothesised that there might be shared genetic variants that confer risk for obese asthma. Arguably, this genetic predisposition may be stronger in childhood, when long-term external factors have had less cumulative effects on overall health and disease status. Initial candidate gene studies yielded some encouraging results, including the genes for protein $\mathrm{C} \mathrm{ki-}$ nase alpha $(P R C K A)$ and leptin $(L E P)^{88,89}$. The gene for the beta-adrenergic receptor 3 (ADRB3) was also reported to modify the association between obesity and asthma ${ }^{90}$. The advent of genome-wide association studies (GWAS), however, did not add considerably to the list of potential candidates. The largest GWAS to date, which included upwards of 23,000 children and adults, reported gene DENN-domain containing $1 \mathrm{~B}$ (DENND1B, also known as connecdenn 2) to be associated with BMI among asthmatic children ${ }^{91}$; however, the main single nucleotide polymorphism (SNP) in replicated in only two of seven independent cohorts. Thus, it may be that the putative shared genetic link between obesity and asthma is more complex or arises from mechanisms other than single genetic variants. For example, a gene-by-environment analysis reported SNPs in the 17q21 locus that were associated with excess weight only among subjects with asth$\mathrm{ma}^{92}$ and a recent analysis reported that an inversion in locus 16p11.2 conferred increased susceptibility to both asthma and obesity; this inversion was found near candidate genes for both asthma (type 1 IFN and IL-27) and obesity (SH2B1 and APOB48R) ${ }^{93}$. Moreover, a recent pilot study of 32 children found differences in DNA methylation profiles in peripheral blood mononuclear cell (PBMC) between children with and without obesity and asthma ${ }^{94}$.

\section{THE CHALLENGE OF BMI}

Many challenges remain in our quest to understand the obese asthma phenotype (Table 1). While a preponderance of evidence (both observational and experimental) supports an association between obesity and incident or worsening asthma, these results are by no means homogeneous. For epidemiological studies, one of the difficulties stems from our definition of obesity. While simple and convenient, BMI may not be reliable or accurate, particularly in childhood and adolescence. The formula we use (weight/height ${ }^{2}$ ) was proposed in the 1830 s to describe "the average man" rather than to study obesity, and originally included various formulas (including weight ${ }^{2} /$ height $^{5}$ and weight/height ${ }^{3}$ ) for different sex and age groups. The term "body mass index" -and its use to study obesity-did not happen until the 1970s and 1980s. Moreover, conversion to sexand age-adjusted percentiles or z-scores may not suffice. For obese children and adolescents, BMI percentiles or z-scores correlate poorly with other measures of adiposity ${ }^{3}$. Childhood obesity researchers have proposed different indicators, including the use of BMI as relative to the $95^{\text {th }}$ percentile (either as a percent [\%BMIp95] or as a difference [ABMIp95]) 4 ; others have proposed the use of a triponderal mass index (TMI, weight/height $\left.{ }^{3}\right)^{5}$. In obese asthma research, this is reflected in several studies that have reported improved results 
TABLE 1. Challenges in obese asthma

Syndrome heterogeneity
- Multiple, complex underlying pathways
- Important modifying factors such as sex and age
- Confounding factors (e.g. socioeconomic and environmental
exposures) are difficult to disentangle
Definition/evaluation of obesity
- Definition based on body mass index (BMI) alone is insufficient
- Need for better means to evaluate/define obesity
- Improved adiposity assessment
- Biomarkers of metabolic dysregulation
Cause and effect
- Ample evidence that obesity leads to increased asthma risk and
severity
- In some instances, poorly controlled asthma may also
predispose to obesity
- Both obesity and asthma could be consequences of early-life
changes
- Obesity-related symptoms (e.g., dyspnoea) could lead to asthma
misdiagnosis
Management challenges
- Weight loss likely effective but larger trials needed with
- Fundardized definitions and outcomes
(e.g. metformin, anti-interleukin (IL)-6 or other biologicals)

when using markers of central obesity such as waist circumference or waist-to-hip ratio ${ }^{95}$, neck circumference ${ }^{96,97}$, skinfold-derived calculations of body fat ${ }^{48}$, ultrasound ${ }^{98}$, or dual-energy X-ray absorptiometry (DXA) ${ }^{98,99}$. Improved ways to evaluate obesity, as well as increased recognition of different adiposity distribution patterns, may improve our understanding of the impact of obesity on asthma.

\section{THE QUESTION OF SEX}

As is the case with many conditions, sex is an important modifier in both asthma and obesity. Asthma incidence is higher in boys than in girls until puberty/adolescence but becomes higher in women than in men afterwards. Likewise, many have reported sex-dependent associations between obesity and asthma outcomes. Some studies have reported that high BMI or other measures of obesity are associated with asthma in boys but not in girls ${ }^{12,96}$, while others have reported associations only in girls ${ }^{100}$; some have even proposed a distinct asthma phenotype in obese girls with early menarche ${ }^{101}$. Furthermore, we and others have reported that the effect of obesity on lung function appears to be more pronounced among boys $^{32,38}$. However, it is still unclear whether these inconsistencies are the result of differing populations, or whether some characteristics or sub-phenotypes of obese asthma truly differ by sex. For example, alterations in the production or effect of sex hormones may mediate some associations seen in obese asthma and may partly explain why some sex associations vary according to age. In either case, varying proportions of males and females could potentially explain inconsistent results across studies.

\section{THE ISSUE WITH CAUSE AND EFFECT}

Most epidemiological observational studies are only able to report associations, rather than adjudicate causality. While many large, longitudinal studies have demonstrated that obesity (or increased adiposity) often precedes incident asthma $^{10-18}$, this does not preclude the possibility that both diseases might be consequence of an earlier cause (for example, early-life exposures, changes in the microbiome, or alterations in the immune system). Mendelian randomization studies in both children and adults have demonstrated that BMI/obesity is causally associated with asthma risk ${ }^{102,103}$. Furthermore, basic science research and experimental data have described causal pathways between obesity and asthma that are beyond the scope of this review. However, even this evidence does 
not preclude that, in some groups, the relationship might be inverted. A recent study in over 2,000 children reported that those with asthma were at higher risk of incident obesity over 10 years of follow-up ${ }^{104}$; although in that study the risk of obesity was driven by children who were already overweight at baseline, in certain cases asthma may indeed be a risk factor for subsequent obesity. With increased attention to the obese asthma phenotype, other studies may report similar results, and we hope that such reports will help us understand whether these constitute specific sub-phenotypes of this syndrome.

Along with obesity-preceding-asthma and asthma-preceding-obesity, obesity in and of itself could lead to symptoms that mimic or confound asthma, such as shortness of breath and dyspnoea on exertion; these could in turn lead to a misdiagnosis of asthma when it does not exist ${ }^{105,106}$. Finally, it could be that in certain people both diseases simply coexist, without necessarily worsening each other.

\section{THE QUEST FOR MANAGEMENT APPROACHES}

While considerable amount of research exists both on the clinical aspects of obese asthma and its potential underlying pathways, very little is known in terms of how to best manage these patients. We have reported that obese school-aged children with asthma have reduced ICS response, but a recent study reported that ICS use in obese preschool children with asthma was associated with fewer exacerbations and symptom days ${ }^{107}$. There have been some suggestions that obese individuals with asthma may have a preserved response to leukotriene inhibitors ${ }^{108,109}$, but others have shown that ICS are still more effective ${ }^{110}$. More recently, studies in adults with severe asthma have reported that obese patients are less likely to respond to omalizumab, with reduced response in lung function, asthma control, and $\mathrm{FeNO}^{111}$. It is important to note that most of these studies were based on post hoc analyses of trials that were not specifically designed to study the differential response between obese and non-obese asthmatics. To the best of our knowledge, to date there have been no clinical trials specifically designed to evaluate whether a higher dose or a specific treatment approach works better among obese children with asthma. Until we have such answers, most patients with obese asthma are likely to benefit from standard, guideline-based, stepwise asthma management, but providers should remember to closely and continuously assess each patient's clinical response.

There have been very few RCTs of weight loss for children/adolescents with obesity and asthma ${ }^{112-114}$, all with very small sample sizes, assessment of diverse interventions, and different outcomes. Yet these preliminary studies show that diet, exercise, or both, may indeed improve asthma-related outcomes in these patients. A handful of RCTs in adults have shown similar results ${ }^{115}$. Hasegawa et al. ${ }^{116}$ showed that bariatric surgery in subjects with obesity and asthma led to $50-70 \%$ reduction in emergency room (ER) visits and hospitalisations for asthma in the two years following the surgery. Larger, multi-centre, RCTs with uniform interventions and standardized outcomes are needed to elucidate the best approach to obese asthma. Until then, it is critical for clinicians to not just manage asthma symptoms, but also to screen and decidedly manage overweight 
or obesity. The ability to participate in healthy physical activity is not only a goal of asthma management, but it should be particularly encouraged in patients with obese asthma.

Alternative approaches may also prove to be helpful. Some observational studies have reported that metformin, an antidiabetic agent, use is associated with improved asthma control and fewer exacerbations among adults with diabetes and asthma ${ }^{117,118}$. More recently, metformin has been reported to improve obesity outcomes in children and adolescents ${ }^{119-121}$. While preliminary, these results suggest that the use of metformin and similar medications could represent new agents for management of obese asthma. Similarly, IL-6 is associated with asthma severity in obese adults with metabolic dysregulation ${ }^{61}$ and thus biological agents that block IL-6 actions could prove to be clinically helpful. As we continue to expand our understanding of obese asthma, so will the potential therapeutic targets for our patients.

\section{CONCLUSIONS}

Obese asthma is a complex, heterogeneous phenotype with multiple underlying pathways. While recognition and understanding of obese asthma have markedly increased over recent years, several challenges remain (see Table 1). Future research should focus on such challenges:

- Improved assessment of obesity and obesity-related metabolic complications that predispose to obese asthma;

- Identification of obese asthma sub-phenotypes, including similarities and differences by sex across different age groups;
- Evaluation of the role of epigenetic regulation in obese asthma, in response to environmental factors among susceptible individuals;

- Study of microbiome changes that may link obesity to asthma, or that may independently predispose to both obesity and asthma;

- Larger clinical trials of weight management for obese asthma, using standardized definitions, approaches, and outcomes;

- Identification of alternate management approaches, including those aimed at ameliorating metabolic and inflammatory pathways in obese asthma.

\section{SOURCES OF FUNDING}

Dr. Forno's contributions were funded in part by grants HL125666 from the U.S. National Institutes of Health (NIH), and from the Klosterfrau Foundation. Dr. Celedón's contributions were funded in part by grants HL117191, HL119952, and MD011764 from the U.S. NIH.

\section{CONFLICTS OF INTEREST}

Dr. Juan Celedon reports grants from Merck and GSK to provide medications free of cost to participants in NIH-funded studies, and non-financial support from Pharmavite (donation of vitamin $\mathrm{D}$ and placebo tablets for an NIH-funded study), outside the submitted work. Dr. Erick Forno has not relevant conflicts of interest to disclose.

\section{REFERENCES}

1. Childhood Obesity. 2016.] Available from https://www.cdc.gov/obesity/ childhood/index.html.

2. Posso M, Brugulat-Guiteras P, Puig T et al. [Prevalence and determinants of obesity in children and young people in Catalonia, Spain, 2006-2012]. Med Clin (Barc). 2014;143:475-83. 
3. Freedman DS, Butte NF, Taveras EM et al. BMI z-Scores are a poor indicator of adiposity among 2- to 19-year-olds with very high BMIs, NHANES 1999-2000 to 2013-2014. Obesity (Silver Spring). 2017;25:739-46.

4. Freedman DS, Butte NF, Taveras EM, Goodman AB, Ogden CL, Blanck HM. The Limitations of Transforming Very High Body Mass Indexes into z-Scores among 8.7 Million 2- to 4-Year-Old Children. J Pediatr. 2017;188:50-6.

5. Peterson CM, Su H, Thomas DM et al. Tri-Ponderal Mass Index vs Body Mass Index in Estimating Body Fat During Adolescence. JAMA Pediatr. 2017;171:629-36.

6. Asthma Data, Statistics, and Surveillance. 2016.] Available from http://www. cdc.gov/asthma/most_recent_data.htm.

7. Pearce N, Ait-Khaled N, Beasley R et al. Worldwide trends in the prevalence of asthma symptoms: phase III of the International Study of Asthma and Allergies in Childhood (ISAAC). Thorax. 2007;62:758-66.

8. Asher MI, Montefort S, Bjorksten B et al. Worldwide time trends in the prevalence of symptoms of asthma, allergic rhinoconjunctivitis, and eczema in childhood: ISAAC Phases One and Three repeat multicountry cross-sectional surveys. Lancet. 2006;368:733-43.

9. Uphoff EP, Bird PK, Anto JM et al. Variations in the prevalence of childhood asthma and wheeze in MeDALL cohorts in Europe. ERJ Open Res. 2017;3.

10. Gilliland FD, Berhane K, Islam T et al. Obesity and the risk of newly diagnosed asthma in school-age children. Am J Epidemiol. 2003;158:406-15.

11. Gold DR, Damokosh AI, Dockery DW, Berkey CS. Body-mass index as a predictor of incident asthma in a prospective cohort of children. Pediatr Pulmonol. 2003;36:514-21.

12. Mannino DM, Mott J, Ferdinands JM et al. Boys with high body masses have an increased risk of developing asthma: findings from the National Longitudinal Survey of Youth (NLSY). Int J Obes (Lond). 2006;30:6-13.

13. Mamun AA, Lawlor DA, Alati R, O'Callaghan MJ, Williams GM, Najman JM. Increasing body mass index from age 5 to 14 years predicts asthma among adolescents: evidence from a birth cohort study. Int J Obes. 2007;31:578-83.

14. Zhang Z, Lai HJ, Roberg KA et al. Early childhood weight status in relation to asthma development in high-risk children. J Allergy Clin Immunol. 2010; 126:1157-62.

15. Weinmayr G, Forastiere F, Buchele G et al. Overweight/obesity and respiratory and allergic disease in children: international study of asthma and allergies in childhood (ISAAC) phase two. PLoS One. 2014;9:e113996.

16. Mebrahtu TF, Feltbower RG, Greenwood DC, Parslow RC. Childhood body mass index and wheezing disorders: a systematic review and meta-analysis. Pediatr Allergy Immunol. 2015;26:62-72.

17. Ho WC, Lin YS, Caffrey JL et al. Higher body mass index may induce asthma among adolescents with pre-asthmatic symptoms: a prospective cohort study. BMC Public Health. 2011;11:542.

18. Flaherman V, Rutherford GW. A meta-analysis of the effect of high weight on asthma. Arch Dis Child. 2006;91:334-9.

19. Aragona E, El-Magbri E, Wang J et al. Impact of Obesity on Clinical Outcomes in Urban Children Hospitalized for Status Asthmaticus. Hosp Pediatr. 2016;6:211-8.

20. Ahmadizar F, Vijverberg SJ, Arets HG et al. Childhood obesity in relation to poor asthma control and exacerbation: a meta-analysis. Eur Respir J. 2016;48:1063-73.

21. van Gent R, van der Ent CK, Rovers MM, Kimpen JL, van Essen-Zandvliet LE, de Meer G. Excessive body weight is associated with additional loss of quality of life in children with asthma. J Allergy Clin Immunol. 2007; 119:591-6.

22. Borrell LN, Nguyen EA, Roth LA et al. Childhood obesity and asthma control in the GALA II and SAGE II studies. Am J Respir Crit Care Med. 2013;187:697-702.

23. Okubo Y, Nochioka K, Hataya H, Sakakibara H, Terakawa T, Testa M. Burden of Obesity on Pediatric Inpatients with Acute Asthma Exacerbation in the United States. J Allergy Clin Immunol Pract. 2016;4:1227-31.

24. Forno E, Lescher R, Strunk R et al. Decreased response to inhaled steroids in overweight and obese asthmatic children. J Allergy Clin Immunol. 2011; 127:741-9.
25. McGarry ME, Castellanos E, Thakur N et al. Obesity and bronchodilator response in black and Hispanic children and adolescents with asthma. Chest. 2015;147:1591-8

26. Harskamp-van Ginkel MW, London SJ, Magnus MC, Gademan MG, Vrijkotte TG. A Study on Mediation by Offspring BMI in the Association between Maternal Obesity and Child Respiratory Outcomes in the Amsterdam Born and Their Development Study Cohort. PLoS One. 2015;10: e0140641.

27. Wilson RM, Marshall NE, Jeske DR, Purnell JQ, Thornburg K, Messaoudi I. Maternal obesity alters immune cell frequencies and responses in umbilical cord blood samples. Pediatr Allergy Immunol. 2015;26:344-51.

28. Malti N, Merzouk H, Merzouk SA, Loukidi B, Karaouzene N, Malti A, et al. Oxidative stress and maternal obesity: feto-placental unit interaction. Placenta. 2014;35:411-6.

29. Costa SM, Isganaitis E, Matthews TJ et al. Maternal obesity programs mitochondrial and lipid metabolism gene expression in infant umbilical vein endothelial cells. Int J Obes (Lond). 2016;40:1627-34

30. Popovic M, Pizzi C, Rusconi F et al. Infant weight trajectories and early childhood wheezing: the NINFEA birth cohort study. Thorax. 2016;71:1091-6.

31. Lazarus R, Colditz G, Berkey CS, Speizer FE. Effects of body fat on ventilatory function in children and adolescents: cross-sectional findings from a random population sample of school children. Pediatr Pulmonol. 1997;24 187-94.

32. Tantisira KG, Litonjua AA, Weiss ST, Fuhlbrigge AL, Childhood Asthma Management Program Research G. Association of body mass with pulmonary function in the Childhood Asthma Management Program (CAMP). Thorax. 2003;58:1036-41.

33. Forno E, Weiner DJ, Mullen J et al. Obesity and Airway Dysanapsis in Children with and without Asthma. Am J Respir Crit Care Med. 2017;195: 314-23.

34. Mead J. Dysanapsis in normal lungs assessed by the relationship between maximal flow, static recoil, and vital capacity. Am Rev Respir Dis. 1980;121: 339-42.

35. Lemaitre F, Clua E, Andreani B, Castres I, Chollet D. Ventilatory function in breath-hold divers: effect of glossopharyngeal insufflation. Eur J Appl Physiol. 2010;108:741-7.

36. Schachter LM, Salome CM, Peat JK, Woolcock AJ. Obesity is a risk for asthma and wheeze but not airway hyperresponsiveness. Thorax. 2001;56:4-8.

37. Sin DD, Jones RL, Man SF. Obesity is a risk factor for dyspnea but not for airflow obstruction. Arch Intern Med. 2002;162:1477-81.

38. Forno E, Han YY, Mullen J, Celedon JC. Overweight, Obesity, and Lung Function in Children and Adults-A Meta-analysis. J Allergy Clin Immunol Pract. 2017.

39. Strunk RC, Colvin R, Bacharier LB et al. Airway Obstruction Worsens in Young Adults with Asthma Who Become Obese. J Allergy Clin Immunol Pract. 2015;3:765-71.

40. Davidson WJ, Mackenzie-Rife KA, Witmans MB et al. Obesity negatively impacts lung function in children and adolescents. Pediatr Pulmonol. 2014; 49:1003-10.

41. Rastogi D, Bhalani K, Hall CB, Isasi CR. Association of pulmonary function with adiposity and metabolic abnormalities in urban minority adolescents. Ann Am Thorac Soc. 2014;11:744-52.

42. Mendelson M, Michallet AS, Perrin C, Levy P, Wuyam B, Flore P. Exercise training improves breathing strategy and performance during the six-minute walk test in obese adolescents. Respir Physiol Neurobiol. 2014;200:18-24

43. Sposato B, Scalese M, Migliorini MG et al. Obesity can influence children's and adolescents' airway hyperresponsiveness differently. Multidiscip Respir Med. 2013;8:60.

44. Karampatakis N, Karampatakis T, Galli-Tsinopoulou A et al. Impaired glucose metabolism and bronchial hyperresponsiveness in obese prepubertal asthmatic children. Pediatr Pulmonol. 2017;52:160-6.

45. Rastogi D, Fraser S, Oh J et al. Inflammation, metabolic dysregulation, and pulmonary function among obese urban adolescents with asthma. Am J Respir Crit Care Med. 2015;191:149-60. 
46. Rastogi D, Holguin F. Metabolic Dysregulation, Systemic Inflammation, and Pediatric Obesity-related Asthma. Ann Am Thorac Soc. 2017;14:S363-S7.

47. Murray CS, Canoy D, Buchan I, Woodcock A, Simpson A, Custovic A. Body mass index in young children and allergic disease: gender differences in a longitudinal study. Clin Exp Allergy. 2011;41:78-85.

48. Forno E, Acosta-Perez E, Brehm JM et al. Obesity and adiposity indicators, asthma, and atopy in Puerto Rican children. J Allergy Clin Immunol. 2014; 133:1308-14, 14 e1-5.

49. Han YY, Forno E, Celedon JC. Adiposity, fractional exhaled nitric oxide, and asthma in U.S. children. Am J Respir Crit Care Med. 2014;190:32-9.

50. Kim SH, Sutherland ER, Gelfand EW. Is there a link between obesity and asthma? Allergy Asthma Immunol Res. 2014;6:189-95.

51. Eising JB, Uiterwaal CS, Evelein AM, Visseren FL, van der Ent CK. Relationship between leptin and lung function in young healthy children. Eur Respir J. 2014;43:1189-92.

52. Huang F, Del-Rio-Navarro BE, Torres-Alcantara S et al. Adipokines, asymmetrical dimethylarginine, and pulmonary function in adolescents with asthma and obesity. J Asthma. 2017;54:153-61.

53. Baek HS, Kim YD, Shin JH, Kim JH, Oh JW, Lee HB. Serum leptin and adiponectin levels correlate with exercise-induced bronchoconstriction in children with asthma. Ann Allergy Asthma Immunol. 2011;107:14-21.

54. Kattan M, Kumar R, Bloomberg GR et al. Asthma control, adiposity, and adipokines among inner-city adolescents. J Allergy Clin Immunol. 2010;125: 584-92.

55. Vijayakanthi N, Greally JM, Rastogi D. Pediatric Obesity-Related Asthma: The Role of Metabolic Dysregulation. Pediatrics. 2016;137.

56. Agrawal A, Mabalirajan U, Ahmad T, Ghosh B. Emerging interface between metabolic syndrome and asthma. Am J Respir Cell Mol Biol. 2011;44:270-5.

57. Dekkers BG, Schaafsma D, Tran T, Zaagsma J, Meurs H. Insulin-induced laminin expression promotes a hypercontractile airway smooth muscle phenotype. Am J Respir Cell Mol Biol. 2009;41:494-504.

58. Cohen P, Noveral JP, Bhala A, Nunn SE, Herrick DJ, Grunstein MM. Leukotriene D4 facilitates airway smooth muscle cell proliferation via modulation of the IGF axis. Am J Physiol. 1995;269:L151-7.

59. Forno E, Han YY, Muzumdar RH, Celedon JC. Insulin resistance, metabolic syndrome, and lung function in US adolescents with and without asthma. J Allergy Clin Immunol. 2015;136:304-11 e8.

60. Nie Z, Jacoby DB, Fryer AD. Hyperinsulinemia potentiates airway responsiveness to parasympathetic nerve stimulation in obese rats. Am J Respir Cell Mol Biol. 2014;51:251-61.

61. Peters MC, McGrath KW, Hawkins GA et al. Plasma interleukin-6 concentrations, metabolic dysfunction, and asthma severity: a cross-sectional analysis of two cohorts. Lancet Respir Med. 2016;4:574-84.

62. Ilmarinen P, Tuomisto LE, Niemela O et al. Comorbidities and elevated IL-6 associate with negative outcome in adult-onset asthma. Eur Respir J. 2016; 48:1052-62.

63. Robinson MB, Deshpande DA, Chou J et al. IL-6 trans-signaling increases expression of airways disease genes in airway smooth muscle. Am J Physiol Lung Cell Mol Physiol. 2015;309:L129-38.

64. Han YY, Forno E, Brehm JM et al. Diet, interleukin-17, and childhood asthma in Puerto Ricans. Ann Allergy Asthma Immunol. 2015;115:288-93 e1.

65. Berentzen NE, van Stokkom VL, Gehring U et al. Associations of sugar-containing beverages with asthma prevalence in 11-year-old children: the PIAMA birth cohort. Eur J Clin Nutr. 2015;69:303-8.

66. Dogaru CM, Nyffenegger D, Pescatore AM, Spycher BD, Kuehni CE. Breastfeeding and childhood asthma: systematic review and meta-analysis. Am J Epidemiol. 2014;179:1153-67.

67. Yan J, Liu L, Zhu Y, Huang G, Wang PP. The association between breastfeeding and childhood obesity: a meta-analysis. BMC Public Health. 2014; $14: 1267$.

68. Garcia-Marcos L, Castro-Rodriguez JA, Weinmayr G, Panagiotakos DB, Priftis KN, Nagel G. Influence of Mediterranean diet on asthma in children: a systematic review and meta-analysis. Pediatr Allergy Immunol. 2013;24: $330-8$.
69. Castro-Rodriguez JA, Forno E, Rodriguez-Martinez CE, Celedon JC. Risk and Protective Factors for Childhood Asthma: What Is the Evidence? J Allergy Clin Immunol Pract. 2016;4:1111-22.

70. Plesner JL, Dahl M, Fonvig CE et al. Obesity is associated with vitamin D deficiency in Danish children and adolescents. J Pediatr Endocrinol Metab. 2018;31:53-61.

71. Boyle VT, Thorstensen EB, Thompson JMD et al. The relationship between maternal 25-hydroxyvitamin D status in pregnancy and childhood adiposity and allergy: an observational study. Int J Obes (Lond). 2017;41:1755-60.

72. Szentpetery SE, Han YY, Brehm JM et al. Vitamin D insufficiency, plasma cytokines, and severe asthma exacerbations in school-aged children. J Allergy Clin Immunol Pract. 2018;6:289-91 e2.

73. Han YY, Forno E, Celedon JC. Vitamin D Insufficiency and Asthma in a US Nationwide Study. J Allergy Clin Immunol Pract. 2017;5:790-6 e1.

74. Rosser F, Brehm JM, Forno E et al. Proximity to a major road, vitamin D insufficiency, and severe asthma exacerbations in Puerto Rican children. Am J Respir Crit Care Med. 2014;190:1190-3.

75. Brehm JM, Acosta-Perez E, Klei L et al. Vitamin D insufficiency and severe asthma exacerbations in Puerto Rican children. Am J Respir Crit Care Med 2012;186:140-6.

76. Litonjua AA, Carey VJ, Laranjo N et al. Effect of Prenatal Supplementation With Vitamin D on Asthma or Recurrent Wheezing in Offspring by Age 3 Years: The VDAART Randomized Clinical Trial. JAMA. 2016;315:362-70.

77. Wolsk HM, Chawes BL, Litonjua AA et al. Prenatal vitamin D supplementation reduces risk of asthma/recurrent wheeze in early childhood: A combined analysis of two randomized controlled trials. PLoS One. 2017;12:e0186657.

78. D’Vaz N, Meldrum SJ, Dunstan JA et al. Fish oil supplementation in early infancy modulates developing infant immune responses. Clin Exp Allergy. 2012;42:1206-16.

79. Li J, Xun P, Zamora D, Sood A et al. Intakes of long-chain omega-3 (n-3) PUFAs and fish in relation to incidence of asthma among American young adults: the CARDIA study. Am J Clin Nutr. 2013;97:173-8.

80. Bailey LC, Forrest CB, Zhang P, Richards TM, Livshits A, DeRusso PA Association of antibiotics in infancy with early childhood obesity. JAMA Pediatr. 2014;168:1063-9.

81. Pitter G, Ludvigsson JF, Romor P et al. Antibiotic exposure in the first year of life and later treated asthma, a population based birth cohort study of 143,000 children. Eur J Epidemiol. 2016;31:85-94.

82. Fujimura KE, Sitarik AR, Havstad S et al. Neonatal gut microbiota associates with childhood multisensitized atopy and T cell differentiation. Nat Med. 2016;22:1187-91.

83. Marsland BJ, Gollwitzer ES. Host-microorganism interactions in lung diseases. Nat Rev Immunol. 2014;14:827-35.

84. Arrieta MC, Stiemsma LT, Dimitriu PA et al. Early infancy microbial and metabolic alterations affect risk of childhood asthma. Sci Transl Med. 2015; 7:307ra152.

85. Vandeputte D, Kathagen G, D’Hoe K et al. Quantitative microbiome profiling links gut community variation to microbial load. Nature. 2017;551:507-11.

86. Elazab N, Mendy A, Gasana J, Vieira ER, Quizon A, Forno E. Probiotic administration in early life, atopy, and asthma: a meta-analysis of clinical trials. Pediatrics. 2013;132:e666-76.

87. Cabana MD, McKean M, Caughey AB et al. Early Probiotic Supplementation for Eczema and Asthma Prevention: A Randomized Controlled Trial. Pediatrics. 2017;140.

88. Murphy A, Tantisira KG, Soto-Quiros ME et al. PRKCA: a positional candidate gene for body mass index and asthma. Am J Hum Genet. 2009;85:87-96

89. Melen E, Himes BE, Brehm JM et al. Analyses of shared genetic factors between asthma and obesity in children. J Allergy Clin Immunol. 2010;126:631-7 e1-8.

90. Kuo NW, Tung KY, Tsai CH, Chen YC, Lee YL. beta3-Adrenergic receptor gene modifies the association between childhood obesity and asthma. J Allergy Clin Immunol. 2014;134:731-3 e3.

91. Melen E, Granell R, Kogevinas M et al. Genome-wide association study of body mass index in 23000 individuals with and without asthma. Clin Exp Allergy. 2013;43:463-74. 
92. Wang L, Murk W, DeWan AT. Genome-Wide Gene by Environment Interaction Analysis Identifies Common SNPs at 17q21.2 that Are Associated with Increased Body Mass Index Only among Asthmatics. PLoS One. 2015; 10:e0144114.

93. Gonzalez JR, Caceres A, Esko T et al. A common 16p11.2 inversion underlies the joint susceptibility to asthma and obesity. Am J Hum Genet. 2014;94:361-72.

94. Rastogi D, Suzuki M, Greally JM. Differential epigenome-wide DNA methylation patterns in childhood obesity-associated asthma. Sci Rep. 2013;3:2164.

95. Chih AH, Chen YC, Tu YK, Huang KC, Chiu TY, Lee YL. Mediating pathways from central obesity to childhood asthma: a population-based longitudinal study. Eur Respir J. 2016;48:748-57.

96. Maltz L, Matz EL, Gordish-Dressman H et al. Sex differences in the association between neck circumference and asthma. Pediatr Pulmonol. 2016;51:893-900.

97. Hacihamdioglu B, Arslan M, Yesilkaya E, Gok F, Yavuz ST. Wider neck circumference is related to severe asthma in children. Pediatr Allergy Immunol. 2015;26:456-60.

98. den Dekker HT, Ros KPI, de Jongste JC, Reiss IK, Jaddoe VW, Duijts L. Body fat mass distribution and interrupter resistance, fractional exhaled nitric oxide, and asthma at school-age. J Allergy Clin Immunol. 2017;139:810-8 e6.

99. Forno E, Han YY, Libman IM, Muzumdar RH, Celedon JC. Adiposity and Asthma in a Nationwide Study of Children and Adults in the United States. Ann Am Thorac Soc. 2017.

100. Lu KD, Billimek J, Bar-Yoseph R, Radom-Aizik S, Cooper DM, Anton-Culver H. Sex Differences in the Relationship between Fitness and Obesity on Risk for Asthma in Adolescents. J Pediatr. 2016;176:36-42.

101. Castro-Rodriguez JA. A new childhood asthma phenotype: obese with early menarche. Paediatr Respir Rev. 2016;18:85-9.

102. Granell R, Henderson AJ, Evans DM et al. Effects of BMI, fat mass, and lean mass on asthma in childhood: a Mendelian randomization study. PLoS Med. 2014;11:e1001669.

103. Skaaby T, Taylor AE, Thuesen BH et al. Estimating the causal effect of body mass index on hay fever, asthma and lung function using Mendelian randomization. Allergy. 2018;73:153-64.

104. Chen Z, Salam MT, Alderete TL et al. Effects of Childhood Asthma on the Development of Obesity among School-aged Children. Am J Respir Crit Care Med. 2017;195:1181-8

105. Lang JE, Hossain J, Holbrook JT et al. Gastro-oesophageal reflux and worse asthma control in obese children: a case of symptom misattribution? Thorax. 2016;71:238-46.

106. Lang JE, Hossain MJ, Lima JJ. Overweight children report qualitatively distinct asthma symptoms: analysis of validated symptom measures. J Allergy Clin Immunol. 2015;135:886-93 e3.
107. Lang JE, Fitzpatrick AM, Mauger DT et al. Overweight/obesity status in preschool children associates with worse asthma but robust improvement on inhaled corticosteroids. J Allergy Clin Immunol. 2017.

108. Peters-Golden M, Swern A, Bird SS, Hustad CM, Grant E, Edelman JM. Influence of body mass index on the response to asthma controller agents. Eur Respir J. 2006;27:495-503.

109. Farzan S, Khan S, Elera C, Tsang J, Akerman M, DeVoti J. Effectiveness of montelukast in overweight and obese atopic asthmatics. Ann Allergy Asthma Immunol. 2017;119:189-90.

110. Sutherland ER, Camargo CA, Jr., Busse WW et al. Comparative effect of body mass index on response to asthma controller therapy. Allergy Asthma Proc. 2010;31:20-5.

111. Sposato B, Scalese M, Milanese M et al. Factors reducing omalizumab response in severe asthma. Eur J Intern Med. 2018.

112. Jensen ME, Gibson PG, Collins CE, Hilton JM, Wood LG. Diet-induced weight loss in obese children with asthma: a randomized controlled trial. Clin Exp Allergy. 2013;43:775-84.

113. Luna-Pech JA, Torres-Mendoza BM, Luna-Pech JA, Garcia-Cobas CY, Navarrete-Navarro S, Elizalde-Lozano AM. Normocaloric diet improves asthma-related quality of life in obese pubertal adolescents. Int Arch Allergy Immunol. 2014;163:252-8.

114. Willeboordse M, van de Kant KDG, Tan FE et al. A Multifactorial Weight Reduction Programme for Children with Overweight and Asthma: A Randomized Controlled Trial. PLoS One. 2016;11:e0157158.

115. Ulrik CS. Asthma and obesity: is weight reduction the key to achieve asthma control? Curr Opin Pulm Med. 2016;22:69-73.

116. Hasegawa K, Tsugawa Y, Chang Y, Camargo CA, Jr. Risk of an asthma exacerbation after bariatric surgery in adults. J Allergy Clin Immunol. 2015; 136:288-94 e8.

117. Li CY, Erickson SR, Wu CH. Metformin use and asthma outcomes among patients with concurrent asthma and diabetes. Respirology. 2016;21:1210-8.

118. Forno E. Asthma and diabetes: Does treatment with metformin improve asthma? Respirology. 2016;21:1144-5.

119. McDonagh MS, Selph S, Ozpinar A, Foley C. Systematic review of the benefits and risks of metformin in treating obesity in children aged 18 years and younger. JAMA Pediatr. 2014;168:178-84.

120. Pastor-Villaescusa B, Canete MD et al. Metformin for Obesity in Prepubertal and Pubertal Children: A Randomized Controlled Trial. Pediatrics. 2017;140.

121. Marques P, Limbert C, Oliveira L, Santos MI, Lopes L. Metformin effectiveness and safety in the management of overweight/obese nondiabetic children and adolescents: metabolic benefits of the continuous exposure to metformin at 12 and 24 months. Int J Adolesc Med Health. 2016;29. 